\title{
Comparative Study of Oil Quality and Aroma Profiles from Tunisian Olive Cultivars Growing in Saharian Oasis Using Chemometric Analysis
}

\author{
Olfa Dridi Gargouri', Yasmine Ben Rouina', Amir Ben Mansour', Guido Flamini², \\ Bechir Ben Rouina ${ }^{3}$ and Mohamed Bouaziz ${ }^{1,4 *}$ \\ ${ }^{1}$ Laboratoire d'Electrochimie et Environnement, Ecole Nationale d'Ingénieurs de Sfax BP «1173» 3038, Université de Sfax, Sfax, TUNISIE \\ ${ }^{2}$ Dipartimento di Farmacia, via Bonanno 33, 56126 Pisa, ITALY \\ ${ }^{3}$ Unité de Productions Oléicoles et Arboricoles, Institut de l'Olivier de Sfax, TUNISIE \\ ${ }^{4}$ Institut Supérieur de Biotechnologie de Sfax, Université de Sfax, BP «1175»3038, Sfax, TUNISIE
}

\begin{abstract}
Aroma profile, oxidative stability and quality parameters of virgin olive oil from four cultivars (Chemlali, Chetoui, Koroneiki and Rjim), grown in Rjim Maatoug oasis in southern of Tunisia, were studied for the first time. The olive oil samples were obtained during maturation from a crop season (2012-2013). The results showed the quality parameters, i.e., free fatty acid, $U V$ absorbance at 232 and $270 \mathrm{~nm}$, increases during maturation exceeding the upper limit established by the IOOC norm. Chlorophyll and carotenoid pigments tended to decrease during ripening stages. The trend of oxidative stability, total phenols and $O$ diphenols exhibited a reduction of antioxidant activity at more advanced stages of maturity. The marks achieved showed that oil quality degradation is due to the great drought of climate: high temperature, high light intensity and low rainfall. Studied aroma profiles of cultivars were also influenced by severe climatic conditions. Twenty-four compounds were characterized, representing $\mathbf{9 4 . 8 - 9 9 . 8 \%}$ of the total volatiles. In all samples, a strong decrease was observed in aldehydes compounds.
\end{abstract}

Key words: olive oil, Chemlali, Chetoui, Koroneiki, Rjim cultivars, desert climate, volatile compounds, chemometric analysis

\section{Introduction}

The olive tree (Olea europaea L.) is the most important evergreen tree in Tunisia with 70 million olive trees covering 1.7 million hectares of land ${ }^{1)}$, where it is grown traditionally in rain-fed conditions. In fact, the most popular cultivars in Tunisia are Chetoui in the northern regions and Chemlali in the central and southern parts. These two varieties contribute to more than $95 \%$ of the national production of olive oil. Almost all studies on Tunisian virgin olive oil have focused on characterization and/or improvement of these two varieties ${ }^{1-3)}$. Other studies have also examined some of the well-known secondary varieties like Koroneiki ${ }^{4,55}$. Koroneiki (Olea europaea var. Microcarpaalba) variety, as an European cultivar introduced in Tunisia, has been cultivated only during the last decades. However, up to now, there has been a lack of information on the chemical characteristics of several minor varieties that are sustained in restricted areas in different parts of Tunisia. A good example is the case of "Rjim Maatoug", a desert oasis in southern Tunisia, bordering Algeria, which is dominated by four main varieties: Chemlali, Chetoui, Koroneiki and Rjim. Because of the severe pedoclimatic conditions (high temperature, high light intensity and low rainfall), the traditional diet in the region is rather simple and based on some specific plant foods, like cereals or palm fruits as well as olive oil, being the main fat source.

Virgin olive oil (VOO) is extensively consumed thanks to its nutritional value and its organoleptic characteristics. Besides, mention should also be made of its use in medicine, recommended already in ancient times and today for the prevention of cardio-circulatory diseases and for its anti-oxidative capacity and its fatty acid composition ${ }^{2,6,7)}$. Moreover, it is widely known that the chemical composition of virgin olive oil is influenced by genetic factors (cultivar) and environmental conditions (edaphological characteristics and climatic parameters ${ }^{8)}$. Furthermore, the quality of

\footnotetext{
*Correspondence to: Mohamed Bouaziz, Laboratoire d'Electrochimie et Environnement, Institut Supérieur de Biotechnologie de Sfax, BP: 1175. 3038, Université de Sfax, TUNISIE

E-mail: mohamed.bouaziz@fsg.rnu.tn

Accepted July 23, 2016 (received for review December 15, 2015)

Journal of Oleo Science ISSN 1345-8957 print / ISSN 1347-3352 online

http://www.jstage.jst.go.jp/browse/jos/ http://mc.manusriptcentral.com/jjocs
} 
O. D. Gargouri, Y. B. Rouina and A. B. Mansour et al.

olive oil is strongly related to the physiological conditions of the fruit from which it was extracted. The stage of ripening may directly or indirectly affect oil quality. The fruit physiology undergoes changes directly related to the age factor, and these changes alter the oil quality. Moreover, there is an indirect effect ascribed to the action of external agents of deterioration which increases during fruit ripening $^{3,9,10)}$. In fact, as ripening advances certain metabolic processes which involve changes in the profile of certain compounds such as fatty acids, polyphenols, tocopherols, chlorophylls and carotenoids occur. These variations are reflected in the sensory characteristics, especially in the aroma (volatile compounds), the oxidative stability and/or the nutritional value of the final product, and of course, in the quality degree. The distinctive aroma of virgin olive oil is attributed to a large number of chemical compounds of different chemical classes, i.e. aldehydes, alcohols, esters, hydrocarbons, ketones and, probably, to other unidentified volatile compounds ${ }^{11,12}$. The volatile composition of olive oil depends on the levels and activity of the enzymes involved in the various pathways ${ }^{13)}$ which are genetically determined ${ }^{14)}$, the climate and soil type ${ }^{15)}$, the ripening cycle of the fruit ${ }^{10)}$, the processing equipment ${ }^{16)}$, the extraction method and storage conditions ${ }^{17}$. However, the effects of these parameters on profile of aroma-related compounds are still ambiguous. In this context, as Rjim Maatoug is a saharian region, the climate hostility has an influence on the aroma and oil quality. Therefore, the present study focuses on two things: First, comparing the chemical characteristic of virgin oils produced by Chemlali, Chetoui, Koroneiki, and Rjim varieties cultivated in Rjim Maatoug region at different ripening degree. Second, studying the influence of saharian conditions on the formation of volatiles profiles of produced virgin oils.
Table 1 Soil characteristics of the experimental site (Rjim Maatoug Oasis).

\begin{tabular}{lrr}
\hline & \multicolumn{2}{c}{ Amplitude $(\mathrm{cm})$} \\
\hline Parameters \% & 30 & 270 \\
Coarse Sand & 25 & 21 \\
Fine Sand & 70 & 73 \\
Clay & 1 & 2 \\
Coarse Silt & 3 & 3 \\
Fine Silt & 1 & 1 \\
Gypsum & 1.4 & 2.06 \\
Calcuim Carbonate & 3.75 & 6.01 \\
\hline
\end{tabular}

\section{Materials and methods}

\subsection{Plant material and site description}

Olive fruits (Olea europaea L.) of the olive oil cultivars Chetoui, Chemlali, Koroneiki and Rjim were collected from trees in the same oasis "Rjim Maatoug" (120 km west of the Kebili region in southern Tunisia).Rjim Maatoug region is located at an altitude of about $50 \mathrm{~m}$ above sea level $\left(33^{\circ} 19^{\prime}\right.$ $19^{\prime} 22 \mathrm{~N}-7^{\circ} 58^{\prime} 39^{\prime \prime} 62 \mathrm{E}$ ). Trees were subjected to the same fertilization and common olive cultivation practices. The soil of Rjim Maatoug oasis region was discriminated by a special granulometry with dominance of sand quantity (Table 1). Therefore, the sandy soils of this region are highly permeable $(15-20 \mathrm{~cm} / \mathrm{h})$ and have a low water-retention capacity [5-6\% (w/w) of dry soil], making them suitable for olive trees which are grown in arid zones.

Climatic conditions during a crop season(2012-2013), presented in Table 2, shows that Rjim Maatoug's climate was characterized by cold winters and irregular rains during the cold seasons which reduce precipitation. These

Table 2 Climatic conditions of the experimental site(Rjim Maatoug Oasis). Monthly values are the average of two consecutive years (2012-2013).

\begin{tabular}{lccc}
\hline \multirow{2}{*}{ Date } & \multicolumn{3}{c}{ Climatic Conditions } \\
\cline { 2 - 4 } & Temperature ${ }^{\circ} \mathrm{C}$ & Pluviometry $(\mathrm{mm})$ & Insolation $(\mathrm{h})$ \\
\hline January & $6.3-16.7$ & 13 & 202 \\
February & $8.2-19.4$ & 9 & 199 \\
March & $10.4-22.3$ & 11 & 236 \\
April & $13.8-26.4$ & 8 & 243 \\
May & $18-31.2$ & 11 & 282 \\
June & $22.3-36.3$ & 2 & 279 \\
July & $24.8-39.1$ & 0 & 332 \\
August & $25.1-38.9$ & 0 & 310 \\
September & $22.2-34.4$ & 13 & 264 \\
October & $17.0-28.2$ & 10 & 239 \\
November & $11.1-21.7$ & 10 & 201 \\
December & $6.8-17.2$ & 12 & 202 \\
\hline
\end{tabular}




\section{Influence of desert climate on olive oil quality}

data prove the Saharian character and the very dry climate throughout the whole year. Summer in this region (between June and September) is very hot (temperature higher than $39^{\circ} \mathrm{C}$ ). Rjim Maatoug's climate is characterized by hot and dry winds, strong insolation ( $\approx 3000$ h/year) and evapo-transpiration followed by absolute drought during six months (from May to October) which affect crops and disrupt their metabolic mechanisms. Therefore, the desert climate of the study area is hostile to the growth and production of any plant species grown outside oasis and without irrigation.

In all olive trees studied, irrigation treatment was carried out by a drip irrigation system with $3000 \mathrm{~m}^{3} /$ hectare/year. The ground water used for irrigation had a pH of 7.39, an alkalinity of $151 \mathrm{mg} / \mathrm{L}$ and an electrical conductivity of 5.5 $\mathrm{mS} / \mathrm{cm}$. The concentration $(\mathrm{mg} / \mathrm{L})$ of the main ions was 590 $\mathrm{Ca}^{2+} ; 460 \mathrm{Na}^{+} ; 185 \mathrm{Mg}^{2+} ; 2450 \mathrm{SO}_{4}{ }^{2-} ; 705 \mathrm{Cl}^{-} ; 14 \mathrm{NO}_{3}{ }^{2-}$ and $3.4 \mathrm{~F}^{-}$.

\subsection{Samples}

Olive fruits were hand-picked at three different stages of maturity, corresponding to October (first Harvest Date $\mathrm{HD}_{1}$ ), November (second Harvest Date $\mathrm{HD}_{2}$ ) and December (third Harvest Date $\mathrm{HD}_{3}$ ) from a crop season (2012-2013). Only healthy fruits, without any kind of infection or physical damage, were processed. After harvesting, fresh olives (1.5-2.0 kg) were deleafed and washed. Olive oils were extracted with a laboratory mill consisting of a two-phase decanter centrifuge. All oil samples were stored at $4{ }^{\circ} \mathrm{C}$ in the dark, using amber glass bottles without headspace, until analysis. The olive maturity index (MI) was determined according to the method developed by Boskou et al. ${ }^{18)}$ based on the evaluation of the olive skin and pulp colors. MI values range from 0 (100\% intense green skin) to $7(100 \%$ purple flesh and black skin).

\subsection{Chemicals and reagents}

Methanol, hexane, and cyclohexane HPLC grade solvents were purchased from Riedel-deHaen-Switzerland. The solvents were of appropriate purity. The 2,2-diphenyl-1-picrylhydrazy (DPPH) and gallic acid were purchased from Sigma-Aldrich (Chemie Gmbh, Steinhein, Germany). FolinCiocalteu reagent was obtained from Fluka (Switzerland).

\subsection{Analytical indices}

The determination of free fatty acid (given as \% of oleic acid), $K_{232}$ and $K_{270}$ were carried out following the analytical methods described by the International Olive Oil Council $2013^{19)}$.

\subsection{Pigment content}

Chlorophyll and carotenoids were determined calorimetrically as previously described by Minguez-Mosquera et $a l .^{20)}$. The maximum absorption at $670 \mathrm{~nm}$ is related to the chlorophyll fraction and that at $470 \mathrm{~nm}$ is related to the carotenoids fraction. The values of the coefficients of the specific applied extinction were $\mathrm{E}_{0}=613\left(\mathrm{~kg} \mathrm{mg}^{-1} \mathrm{~cm}^{-1}\right)$ for pheophytin as a major component in the chlorophyll fraction, and $\mathrm{E}_{0}=2000\left(\mathrm{~kg} \mathrm{mg}^{-1} \mathrm{~cm}^{-1}\right)$ for lutein as a major component in the carotenoids fraction. The pigment contents were calculated as follows:

$$
\begin{aligned}
& \text { Chlorophyll }(\mathrm{mg} / \mathrm{kg})=\left(\mathrm{A}_{670} \times 10^{6}\right) /(613 \times 100 \times \mathrm{d}) \\
& \operatorname{Carotenoid}(\mathrm{mg} / \mathrm{kg})=\left(\mathrm{A}_{470} \times 10^{6}\right) /(2000 \times 100 \times \mathrm{d})
\end{aligned}
$$

where $\mathrm{A}$ is the absorbance and $\mathrm{d}$ is the spectrophotometer cell thickness $(1 \mathrm{~cm})$.

\subsection{Analysis of phenolic compound}

2.6.1 Extraction of phenolic fraction from olive oil

The phenolic extracts were obtained following the procedure of Chtourou et al. ${ }^{21)}$ with some modification. Briefly, the oil sample $(4 \mathrm{~g})$ was added to $2 \mathrm{~mL}$ of $n$-hexane and 4 $\mathrm{mL}$ of a methanol/water $(60: 40, \mathrm{v} / \mathrm{v})$ solution in a $20 \mathrm{~mL}$ centrifuge tube. After vigorous mixing, they were centrifuged for $3 \mathrm{~min}$. The hydro-alcoholic phase was collected, and the hexanic phase was re-extracted twice with $4 \mathrm{~mL}$ of methanol/water (60:40 v/v) solution each time. Finally, the hydro-alcoholic fractions were combined, washed with 4 $\mathrm{mL}$ of $\mathrm{n}$-hexane to remove the residual oil, then concentrated and dried by evaporative centrifuge in vacuum at $35^{\circ} \mathrm{C}$.

\subsubsection{Total phenols and O-diphenols contents}

The determination of the total phenolic compounds was performed by means of the Folin-Ciocalteau reagent and the method that was described by Ammar et al. ${ }^{16)}$. The total phenolic content was expressed as milligrams of gallic acid (GA) equivalent per kilogram of oil. The optical density (OD) is measured at $\lambda=765 \mathrm{~nm}$, carried out using a spectrophotometer (Shimadzu UV-1800 PC, Japan).

The concentration of $O$-diphenols compounds in the methanolic extract was determined by the method described by Gargouri et $a{ }^{22)}$. The total of $O$-diphenols content was expressed as milligrams of gallic acid (GA) equivalent per kilogram of oil. The optical density(OD) is measured at $\lambda=370 \mathrm{~nm}$, carried out using a spectrophotometer (Shimadzu UV-1800 PC, Japan).

\subsubsection{DPPH radical scavenging assay}

The 2,2-diphenyl-1-picrylhydrazyl (DPPH radical) scavenging effect was evaluated according to the method employed by Gargouri et al. ${ }^{1}$. Four milliliters of each sample extract at different concentrations were added to $10 \mathrm{~mL}$ DPPH methanol solution $\left(1.5 \times 10^{-4} \mathrm{M}\right)$. After mixing the two solutions gently and leaving them for $30 \mathrm{~min}$ at room temperature, the optical density was measured at $520 \mathrm{~nm}$ using a Shimadzu UV-160 a spectrophotometer. The test samples were tested and positive control BHT over a range of concentrations. 
The antioxidant activity of each test sample and BHT was expressed in terms of concentration required to inhibit $50 \%$ DPPH radical formation $\left(\mathrm{IC}_{50} \mathrm{mg} / \mathrm{mL}\right.$ ) and calculated from the log-dose inhibition curve.

\subsection{Determination of oxidative stability by Rancimat method}

The oil samples (5.0 g) were heated in a Rancimat equipment at $215^{\circ} \mathrm{C}$ (Metrohm Ltd., Herisau, Switzerland), with a continuous air flow of $20 \mathrm{~L} / \mathrm{h}$ passing through the samples. The conductivity cells were filled with $60 \mathrm{~mL}$ of deionized water. The time needed (hours) for the appearance of a sudden water conductivity rise, caused by the adsorption of volatiles derived from oil oxidation, was registered as the induction time.

\subsection{Volatiles compounds analyses}

-Extraction: Solid-phase micro extraction was used as a technique for headspace sampling of virgin olive oils. Supelco SPME devices coated with polydimethyl siloxane (PDMS, $100 \mu \mathrm{m}$ ) were used to sampling the headspace of 2 $\mathrm{mL}$ of olive oil inserted into a $5 \mathrm{~mL}$ glass septum vial and allowed to equilibrate for $30 \mathrm{~min}$ at $22 \pm 1^{\circ} \mathrm{C}$. After the equilibration time, the fibre was exposed to the headspace for $50 \mathrm{~min}$ at $25^{\circ} \mathrm{C}$ room temperature. Extraction temperature and times were optimised in previous studies ${ }^{14)}$.

-Identification: GC analyses were performed using a HP-5890 series II instrument equipped with a DB-5 capillary column $(30 \mathrm{~m} \times 0.25 \mathrm{~mm}$ i.d., $0.25 \mu \mathrm{m}$ film thickness $)$, working with the following temperature program: $60^{\circ} \mathrm{C}$ for $10 \mathrm{~min}$, ramp of $5^{\circ} \mathrm{C} \min ^{-1}$ to $220^{\circ} \mathrm{C}$; injector and detector temperatures, $250^{\circ} \mathrm{C}$; carrier gas, helium $\left(1 \mathrm{~mL} \mathrm{~min}^{-1}\right)$; detector FID; splitless injection. The components were identified by the comparison of their retention times with those of pure authentic standards and by means of their linear retention indices (LRI) relative to the series of n-hydrocarbons. GC-EIMS analyses were performed using a Varian CP 3800 gas chromatograph equipped with a DB-5 capillary column (30 m × $0.25 \mathrm{~mm}$ i.d., $0.25 \mu \mathrm{m}$ film thicknesses $)$ and a Varian Saturn 2000 ion trap 200 mass detector. Analytical conditions were as follows: injector and transfer line temperature at 250 and $240^{\circ} \mathrm{C}$, respectively; oven temperature was programmed from 60 to $240^{\circ} \mathrm{C}$ at $3^{\circ} \mathrm{C} \mathrm{min}^{-1}$; carrier gas, helium at $1 \mathrm{~mL} \mathrm{~min}^{-1}$; split less injection. The identification of the constituents was based on the comparison of the retention times with those of authentic samples, comparing their LRI relative to the series of n-hydrocarbons, and on computer matching against commercial(NIST 98 and ADAMS) and homemade library mass spectra built from pure substances and components of known oils and MS literature data ${ }^{23)}$. Moreover, the molecular weights of all the identification substances were confirmed by GC-CIMS, using $\mathrm{MeOH}$ as CI ionizing gas ${ }^{24)}$.

\subsection{Statistical analysis}

The results were expressed as mean \pm standard deviation (SD) of three measurements for the analytical determination. Significant differences between the values of all parameters were determined at $p<0.05$ according to the one-way ANOVA: Student Newman-Keuls test, using SPSS Statistics 17.0 for Windows (SPSS Inc., 2008).

Non-standardized principal component analysis (PCA) was applied to show the effect of all the investigated parameters $(n=32)$ : Free fatty acids, $K_{232} ; K_{270}$; chlorophylls; carotenoids; total phenols; $O$-diphenols; oxidative stability; antioxidant activity; hexanal; $(E)$-2-hexenal; $(Z)$-2decenal; Nonanal; $(E)$-2-hexen-1-ol; $(E)$-3-hexen-1-ol; 1-hexanol; 1-pentanol; 1-heptanol; $(Z)$-3-hexenyl acetate; 1-hexyl acetate; n-octane; $n$-decane; $n$-dodecane; $n$-tridecane; $n$-tetradecane; $(E)$-2-dodecene; camphor; 2-decanone; 6-methyl-5-hepten-2-one; 2-methyl-6-methylene-1,7octadien-3-one; $\beta$-selinene and $(E, E)$ - $\alpha$-farnesene, on the olive oils of the different regions using the Varimax rotation with Kaiser Normalization. The PCA type was Pearson(n), the biplot type was correlation biplot and the coefficient was automatic.

A uniform hierarchical cluster analysis (HCA) methodology was applied on data. Each cluster was determined by the following parameters: similarity, Euclidean distance matrix and the Ward's method, generating a dendrogram for olive oil samples. All the chemometric analyses were performed using XLSTAT software for Windows (v.2013.2.03, Addinsoft, New York, USA).

\section{Results and Discussion}

\subsection{Quality parameters}

Table 3 shows the change in the physicochemical quality parameters of the samples during maturation. Free fatty acid, specific absorptions at 232 and $270 \mathrm{~nm}$, pigments and phenols contents were well-investigated at harvest dates.

Free fatty acid is an important quality factor that has been extensively used as a traditional criterion for classifying olive oil in various commercial grades. In fact, the free fatty acid of different olive oils cultivars varied during maturation. For each variety, an increase in free fatty acid values was observed as ripening advanced, with significant differences between the first and the last stage of ripeness (Table 3). The values ranged between 0.82 at $\mathrm{HD}_{1}$ and 1.90 at $\mathrm{HD}_{3}$ for Koroneiki cultivar. As a matter of fact, during the olive ripening there is a progressive activation of lipolytic activity and olives are more sensitive to pathogenic infections and mechanical damage, which results in oils with higher acidity values ${ }^{25)}$. Table 3 also reveals that the free fatty acid content of all analyzed samples was above $0.8 \%$ and fell within the accepted value for virgin olive oils ${ }^{19)}$. The higher acidity values of samples can be explained by 


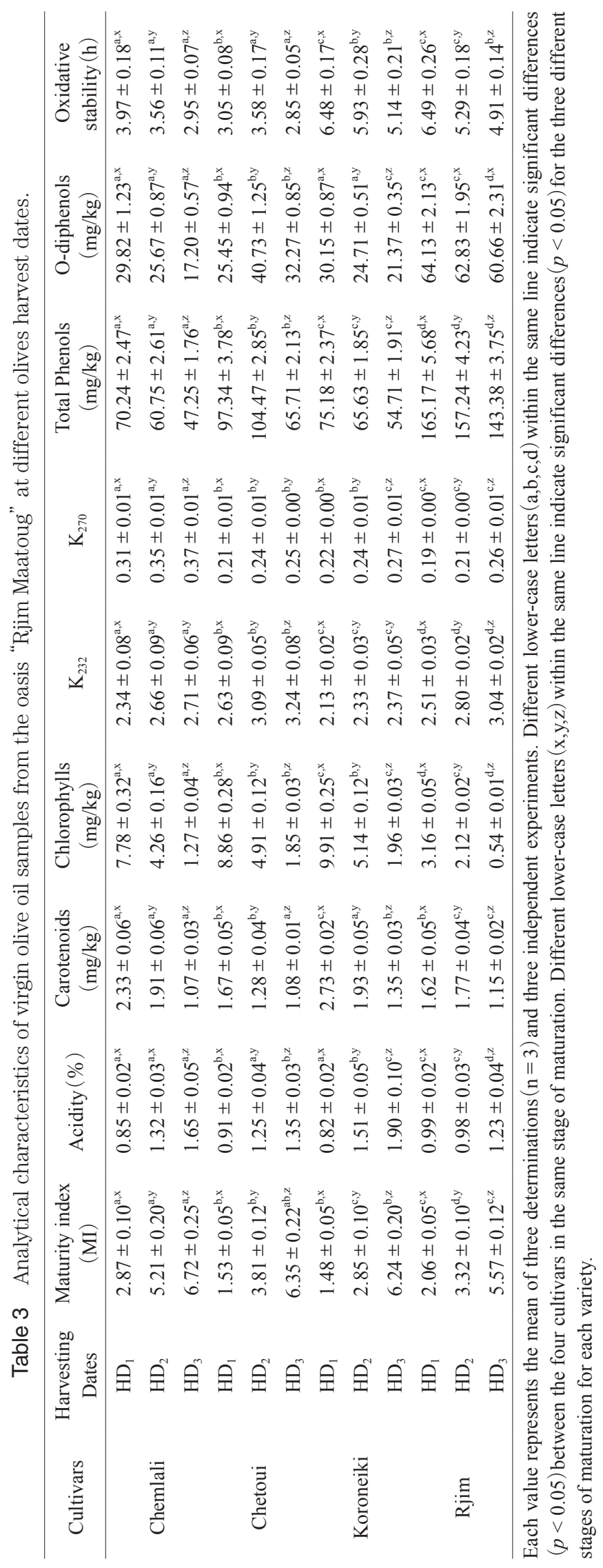


severe climatic conditions related essentially to high temperature with strong insolation prevailing during several months in the oasis of Rjim Maatoug. This effect inhibits the olive oil lipogenesis which leads to the degradation of oleic acid (C18:1). In this context, it has been reported by Rondanini $e t ~ a l .{ }^{26)}$ that high temperature during the oil accumulation period in olive can be negatively correlated with oleic acid content at harvest. Experiments under controlled conditions would greatly contribute to our understanding of how oil quality is influenced by environmental factors.

Measurements of absorbance at specific wavelengths in the UV region are used to provide information on the quality of olive oil. All olive oils are required to have extinction coefficients at 232 and $270 \mathrm{~nm}$, respectively, more than 2.50 and 0.25 . The previously mentioned Table 3 indicates that in all samples, the specific extinction $\mathrm{K}_{232}$ and $\mathrm{K}_{270}$ increased with the maturity index exceeding the upper limit established by the IOOC norm. $\mathrm{K}_{232}$ varied between 2.13 at $\mathrm{HD}_{1}$ for Koronaiki cultivars and 3.04 at $\mathrm{HD}_{3}$ for Rjim cultivars. Nevertheless, $\mathrm{K}_{270}$ varied between 0.19 at $\mathrm{HD}_{1}$ and 0.37 at $\mathrm{HD}_{3}$ for Rjim and Chemlali cultivars, respectively. Thus, samples are classified with virgin and ordinary olive oil category.

Therefore, all parameters quality studied exceeding the upper limit established by the IOOC norm reveal that oil quality is influenced by climatic conditions practically the high temperature. In the same vein, other research has demonstrated that composition of the olive oil could change and oil quality could reduce in arid and semi-arid areas by heat stress and scarcity of water ${ }^{27)}$.

\subsection{Pigment contents}

In olive oils, chlorophyll and carotenoid pigments are mainly responsible for the color of olive oil, which varies from yellow-green to greenish gold ${ }^{28)}$. Furthermore, pigments are also involved in olive-oil oxidative stability ${ }^{29)}$. The degree of olives ripening is crucial for pigment concentrations in olive oil. The content of chlorophyll pigments and carotenoids decreased markedly during maturity stage. For the studied oils, chlorophylls were found at average concentrations between 0.54 and $9.91 \mathrm{mg} / \mathrm{kg}$ whereas the average concentration of carotenoids varied between 1.07 and $2.73 \mathrm{mg} / \mathrm{kg}$ according to varieties (Table 3 ). Chemlali, Chetoui and Koroneiki cultivars present higher amounts in chlorophylls than Rjim at the same stage of maturity $\mathrm{HD}_{1}$. However, the highest amounts of carotenes were observed in the oils of Chemlali and Koroneiki varieties at $\mathrm{HD}_{1}$. These results agree with the finding by other authors ${ }^{10,30}$. Indeed, as ripening progresses, photosynthetic activity decreases, and the level of both chlorophylls and carotenoids decreases progressively accompanied with the formation of other coloured compounds, such as anthocyanins.

\subsection{Phenol and O-diphenol contents}

The phenolic compounds present in virgin olive oil are one of the bases of the nutritional importance and shelf life of this oil. The $O$-diphenol family could be identified as the main source of the overall antioxidant activity and sensorial properties of olive oils ${ }^{31)}$.

The highest contents of these components were detected in Rjim oil, with $165.17 \mathrm{mg} / \mathrm{kg}$ at $\mathrm{HD}_{1}$, however, the lowest amounts, in the same harvest date, were recorded in Chemlali oils $(70.24 \mathrm{mg} / \mathrm{kg})$. As reported by different authors, the amount of total phenols normally ranges between 50 and $1000 \mathrm{mg} / \mathrm{kg}$, depending on various factors such as cultivar, climatic condition and degree of maturation $^{32)}$. In the same vein, Table 3 reveals that phenols concentration in Chemlali, Koroneiki and Rjim samples decreased during olive maturation. The phenol contents decrease from 165.17 to $143.38 \mathrm{mg} / \mathrm{kg}$ and from 70.24 to $47.25 \mathrm{mg} / \mathrm{kg}$ between $\mathrm{HD}_{1}$ and $\mathrm{HD}_{3}$ for Rjim and Chemlali cultivars, respectively. It is well-known that, in addition to their antioxidant activity, phenolic compounds also contribute to olive oils bitter and pungent taste ${ }^{7)}$. Therefore, the loss in phenolic content during olive ripening may affect olive oils quality. This result is in agreement with other previous researches ${ }^{33,34)}$. Nevertheless, for Chetoui olive oil, the total phenol increased and reached maximum value $(104.47 \mathrm{mg} / \mathrm{kg})$ at $\mathrm{HD}_{2}$ then it decreased. This result has been observed for Chetoui variety planted in other South Tunisian region ${ }^{3)}$. It has been reported by Baccouri et $a l^{3)}$ that the oils analyzed from Chetoui variety presented a similar behaviour: increase in total polyphenol content until the olives reached a red or black pigmentation stage, followed by a decline, as ripening progressed. These results also coincide with those observed in Cornicabra variety ${ }^{35}$. In fact, Salvadoret $a l .^{35)}$, and Morello et $a l^{36)}$, reported that during ripening, the concentration of phenolic compounds increases progressively until it reaches a maximum at the spotted and purple pigmentation after which it decreases. The increase in phenols was explained by the reduction in water content. The activity of enzymes is responsible for phenolic compound synthesis, such as L-phenylalanine ammonia-lyase whose activity is greater under higher water stress conditions. However, its concentration decreases when humidity increases ${ }^{36)}$.

Regarding the $O$-diphenol compounds, the amount behaved similarly to the total phenol evolution during maturity process (Table 3 ) with an increase at the early stages of maturity followed by a decrease at advanced MI as previously described ${ }^{32,33)}$.

\subsection{Oxidative stability}

Stability to oxidation, measured by the Rancimat method, is an important parameter of olive oil which is improved by synergistic interactions between various antioxidants present and the lipid composition. In detail(Table 3), 
the oil oxidative stability during the three crop months varied over the ranges 3.97-2.95 $\mathrm{h}$ (Chemlali), 3.05-2.85 $\mathrm{h}$ (Chetoui), 6.48-5.14 h(Koroneiki) and 6.49-4.91 h (Rjim). Table 3 shows that the highest level was attributed to the Rigim cultivar at HD1. This highest value may be explained by the high phenolic compounds contents ${ }^{37}$. Hence, as observed in total phenol content, the values of oxidative stability of Chetoui oil increased progressively, reached maximum value at $\mathrm{HD}_{2}$, and then it decreased (Table 3). In all tested oils, stability decreased in the last stages of ripening. This trend is explained by the deficiency of natural antioxidants (phenols and $O$-diphenols), as shown previously ${ }^{33)}$.

\subsection{Antioxidant activity of oil extract}

Recently, antioxidants have become a topic of increasing interest to health and food science researchers or medical experts $^{1)}$. To evaluate the antioxidant activity of the phenolic fraction, the well-known DPPH antiradical test was performed (Fig. 1), and as expected, a good correlation with antioxidant power and the phenols content was detected. In fact, cultivar variety and harvest date showed a high influence in antioxidant activity. The highest $\mathrm{IC}_{50}$ $(18.70 \mu \mathrm{g} / \mathrm{mL})$ which indicated a lower antioxidant potential, were observed for the Chemlali samples collected at $\mathrm{HD}_{3}$ (black olive extract). This is probably due to the lower inhibition of the radical formed by a low concentration of O-diphenol compounds (17.2 mg/kg of oil). Rjim samples obtained at $\mathrm{HD}_{1}$ had the highest antioxidant activity with an $\mathrm{IC}_{50}$ value of $10.35 \mu \mathrm{g} / \mathrm{mL}$. It was reported that phenolics concentration was in relationship with the percent of radical inhibition in the measurement of the antioxidant activity $^{1)}$.

\subsection{Volatile compounds}

The characteristic and the unique flavor of virgin olive oil, in particular, its green and fruity attributes depend on many volatile compounds ${ }^{38)}$. Concentration and odor

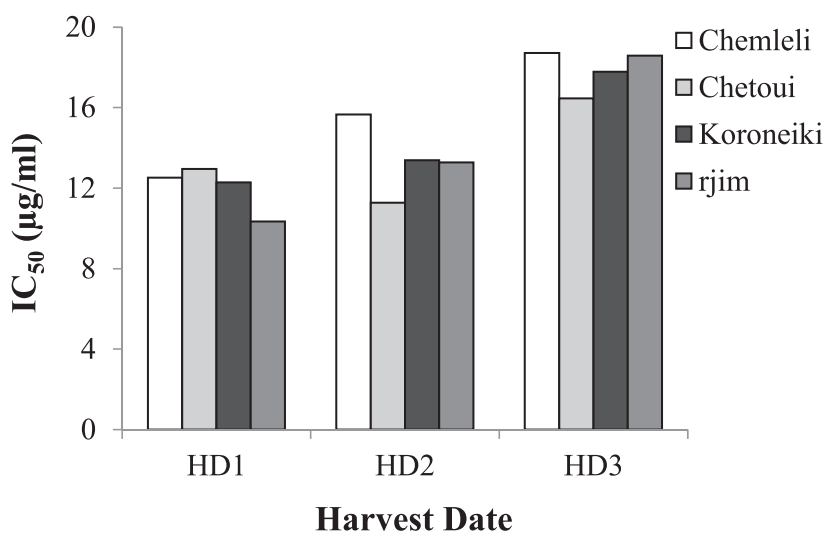

Fig. 1 Free radical scavenging activity of olive oil samples during maturation. threshold of volatile compounds, whether major or minor, are crucial to virgin olive oil quality. Consequently, the identification and the quantification of the compounds causing the flavor or off-flavor are considered the key for quality control. Table 4 displays the compounds identified in the volatile fractions of the oils obtained from the four cultivars of Olea europaea L. (Chetoui, Chemlali, Koroneiki and Rjim) using SPME-GC/MS. It proves that the virgin olive oil headspace consists of a complex mixture of 24 compounds, representing $94.8-99.8 \%$ of the total volatile compounds.

The most important group identified was mainly alcohols with $7.3-42.7 \%$ of the total peak area percentage, aldehydes $(0.7-22 \%)$ as well as esters $(0-26.8 \%)$, which contribute to aroma of olive oil ${ }^{11)}$. Comparing the four olive cultivars collected at the same date and grown under the same pedoclimatic conditions showed a great qualitative and quantitative difference in the volatile fruit contents. The results presented in Table 4 indicate that olive oil volatile compounds accumulate differently, according to the cultivars kind as well as olive ripeness. The present results are in agreement with the previous studies ${ }^{39)}$.

The major volatile compounds responsible for odour notes of virgin olive oils are the $\mathrm{C}_{6}$ and the $\mathrm{C}_{5}$ volatile compounds coming from primary or secondary LOX pathway, respectively ${ }^{13,40)}$. The $\mathrm{C}_{6}$ compounds, also called "green volatiles" ${ }^{40)}$, were quantified in all the analyzed varieties (Table 4). These compounds are derived from the cascade of enzymatic reactions starting with the formation, by lipoxygenase (LOX) action, of 13-hydroperoxides from linoleic and linolenic acid $^{41)}$ and the different accumulations of metabolites from the lipoxygenase cascade were highly dependent on the levels of enzymes involved, the extraction conditions, the storage time and the degree of ripening of olives ${ }^{39)}$. In addition, climatic and environmental growth conditions may also influence the production of volatiles ${ }^{42}$. The chemical compositions of all analyzed olive oil demonstrated that $\mathrm{C}_{6}$ alcohols (hexan-1-ol, $(E)$-2-hexen-1-ol and $(E)$-3-hexen-1-ol) were higher than $\mathrm{C}_{6}$ aldehydes (hexanal and $(E)$-2-hexenal). on the one hand, these results may be explained by differential activity of the enzyme alcohol dehydrogenase which reduces the $\mathrm{C}_{6}$ aldehydes compounds in the corresponding alcohols due, among genetic factors, also to the region of growing of the plants (Tables 1 and 2). On the other hand, the higher content of $\mathrm{C}_{6}$ alcohols was affected by environmental conditions of Rjim Maatoug region which is characterized by high temperature and high light intensity. In fact, with respect to the evolution of $\mathrm{C}_{6}$ alcohols, the $(E)$-2-hexen-1-ol reached maximum values at $\mathrm{HD}_{2}(19.2,25.8$ and $18.3 \%$ for Chemlali, Koroneiki and Rjim, respectively) then decreased in the over-ripe. In Chetoui samples, this compound was not detected during the olive maturation process. The changes in hexanol amounts in the course of fruit ripening were similar in 


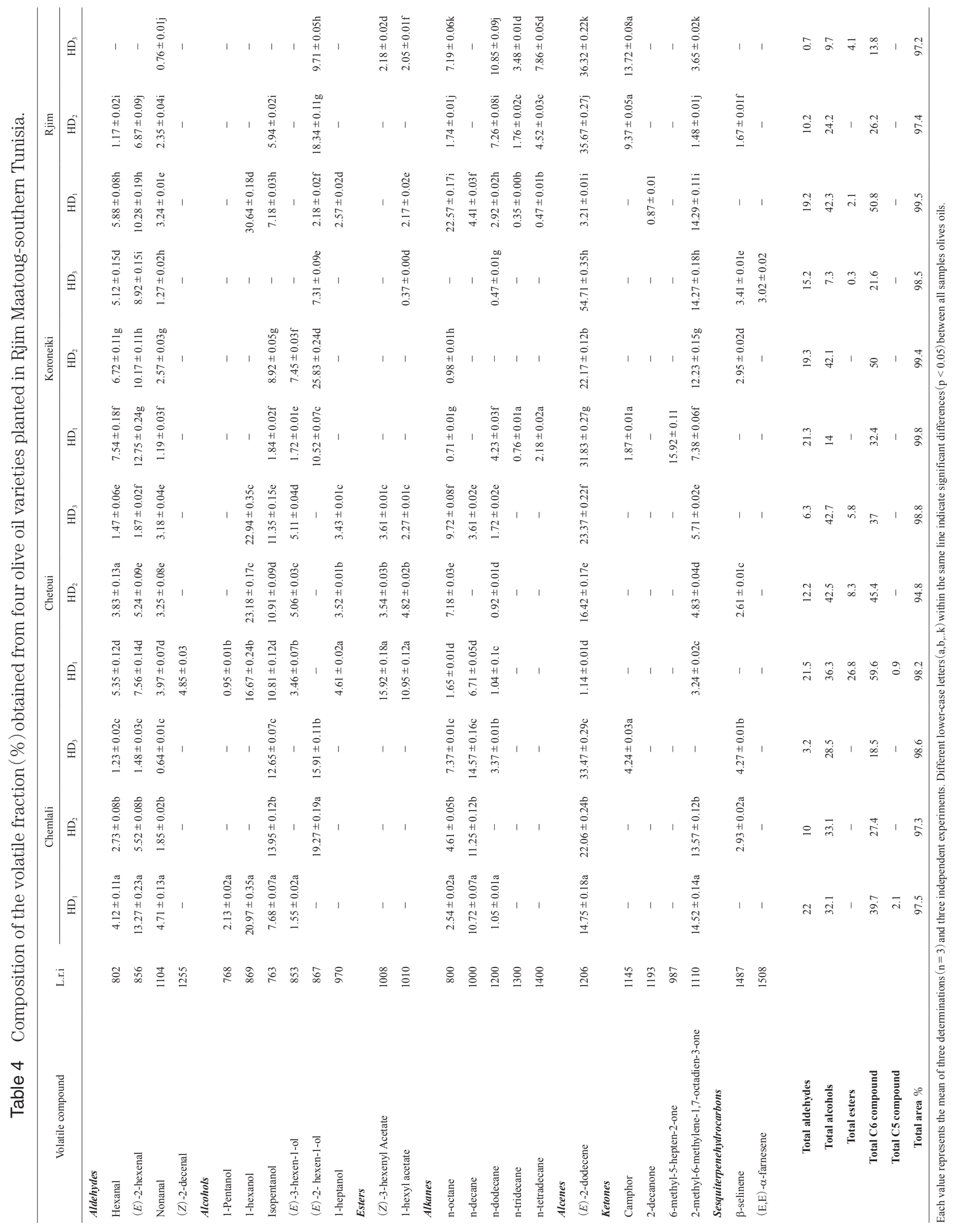




\section{Influence of desert climate on olive oil quality}

Chemlali and Rjim olive oils: a decrease during ripening. However, in Chetoui samples a slight increase was observed (from 16.6 to $23.1 \%$ at $\mathrm{HD}_{1}$ and the $\mathrm{HD}_{2}$, respectively) then a decrease was noted; though, in Koroneiki samples, this alcohol volatile compound was not detected. In this context, other researchers in other VOO cultivars (Picual and Coratina) have not evidenced the moderate increase in the hexanol content $^{38)}$.

In terms of $\mathrm{C}_{6}$ aldehydes, especially $(E)$-2-hexenal and hexanal were detected for all samples with lower percent between $0-13.2 \%$ and $0-7.5 \%$, respectively. Indeed, several researches ${ }^{28,38)}$ proved that $(E)$-2-hexenal is the most abundant volatile compound which is responsible for almond and green sensory notes and offered an attribute positive to Extra Virgin Olive Oil. Nevertheless, all samples in this study presented a contrary behavior. This result is mainly related to the low rainfall (101 mm/year) and high temperature in Rjim Maatoug region which leads to the decrease of soil moisture, leaf water content and gas exchange parameters during summer. Regardless irrigation applied and highly permeable sandy soil, the studied cultivars were strongly affected by the great drought of climate: over- temperature and high light intensity provoke a failure development of olive oil lipogenesis which is blocked early in the season(October). It is also noteworthy that the content of nonanal generally decreased with the ripening degree. These compounds have been associated with the oxidative status of Virgin Olive oil ${ }^{12)}$.

Esters, compounds associated with fruity sensory notes $^{43)}$ as 1-hexyl acetate and $(\boldsymbol{Z})$-3-hexenyl acetate, were present mainly in Chetoui olive oil but they are minor components when compared with aldehydes or alcohols (Table 4). These esters are synthesized by alcohol acetyl transferase within the LOX pathway. Moreover, the low contents of esters in the Chemlali, Koroneiki and Rjim cultivars also point out the absence of alcohol acetyl transferase activity in the olive oils compared with Chetoui varieties (10.9, 4.8, $2.2 \%$ and $15.9,3.5,3.6 \%$ of 1 -hexyl acetate and $Z$-3-hexenyl acetate, respectively, throughout the maturity process) .

Several hydrocarbons were detected in all the analyzed samples. Most of them were minor compounds of the volatile fraction not derived from fatty acid transformations. It is important to note that the main sesquiterpene $(E, E)$ - $\alpha$-farnesene was only detected with low percent in Koroneiki olive oil(3\% at the over-ripe stages). However, hydrocarbons were detected in all samples with mean values varied during the maturity process and cultivars.

Finally, the genetic effect related to the cultivar is one of the most significant aspects of volatile composition of olive oil. However, climatic and agronomic conditions of olive growing can affect volatile composition of olive oils obtained by the same cultivar. Our results are different than other Tunisian work on the same cultivars ${ }^{4,5,44)}$. This difference is explained by the arid climatic conditions of the desert oasis Rjim Maatoug.

\subsection{Chemometric analysis}

PCA was used in exploratory analysis to analyze the effect of cultivar variety and maturity index on the components of the virgin olive oils. The application of the PCA of all analyses performed on olive oil has exhibited three distinct groups (Fig. 2). By observing the eigen values, it can be concluded that two principal components (PC) were sufficient to account for $62.38 \%$ of the total variance (PC1:35.63\%; PC2: 26.75\%). The first group was composed by the Chetoui cultivar at different stages of maturation. The second group was characterized by Chemlali cultivar. Finally, the third group was made up of six samples from Koroneiki and Rjim cultivar. After the Varimax rotation, F1 was dominated by the following variables: Free fatty acids, $\mathrm{K}_{232} ; \mathrm{K}_{270}$; total phenols; O-diphenols; hexanal; Nonanal; 1-hexanol; 1-Pentanol; 1 -hexyl acetate; $n$-decane; n-dodecane; $(E)$-2-dodecene; camphor; 2-methyl-6-methylene-1,7-octadien-3-one and $(E, E)$ - $\alpha$-farnesene. F2 was dominated by the following variables: chlorophylls; carotenoids; oxidative stability; antioxidant activity; $(E)-2$ hexenal; $(Z)$-2-decenal; $(E)$-2-hexen-1-ol; $(E)$-3-hexen1-ol; 1-heptanol; $(Z)$-3-hexenyl acetate; n-octane; ntridecane; n-tetradecane; 2 decanone; 6-methyl-5-hepten2 -one and $\beta$-selinene.

The results obtained were confirmed by performing a Hierarchical Cluster Analysis dendrogram (HCA). In fact, Fig. 3 shows three distinct clusters based on the threshold value (equal to 2100469), with a high similarity between Rjim and Koroneiki cultivars at different stages of maturation, whereas Chemlali and Chetoui cultivar presented an extreme dissimilarity in their composition between them and in comparison to the other cultivars. In this case, the

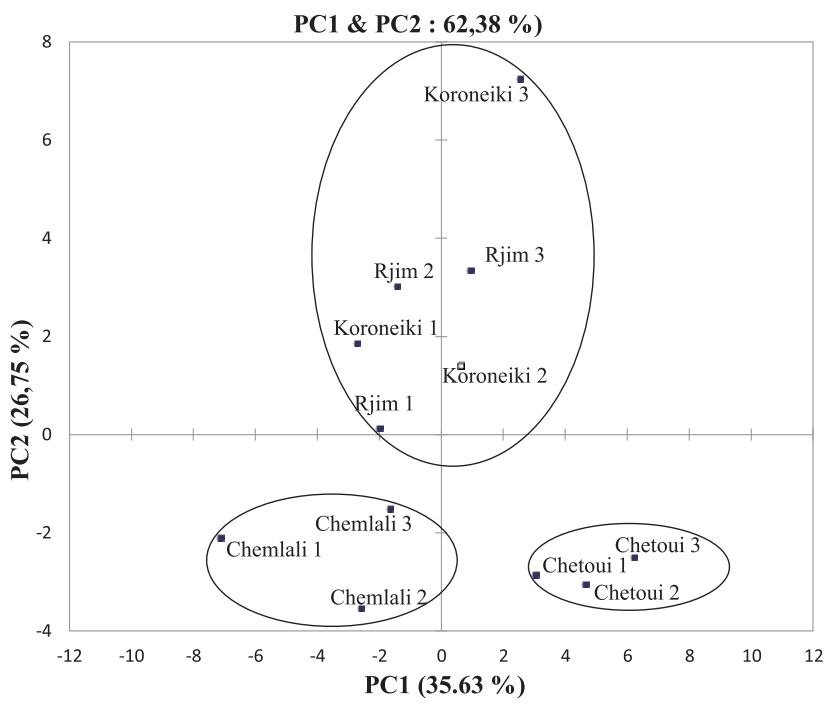

Fig. 2 Principal component analysis (PCA) of the studied cultivars at different stages of maturation. 
O. D. Gargouri, Y. B. Rouina and A. B. Mansour et al.

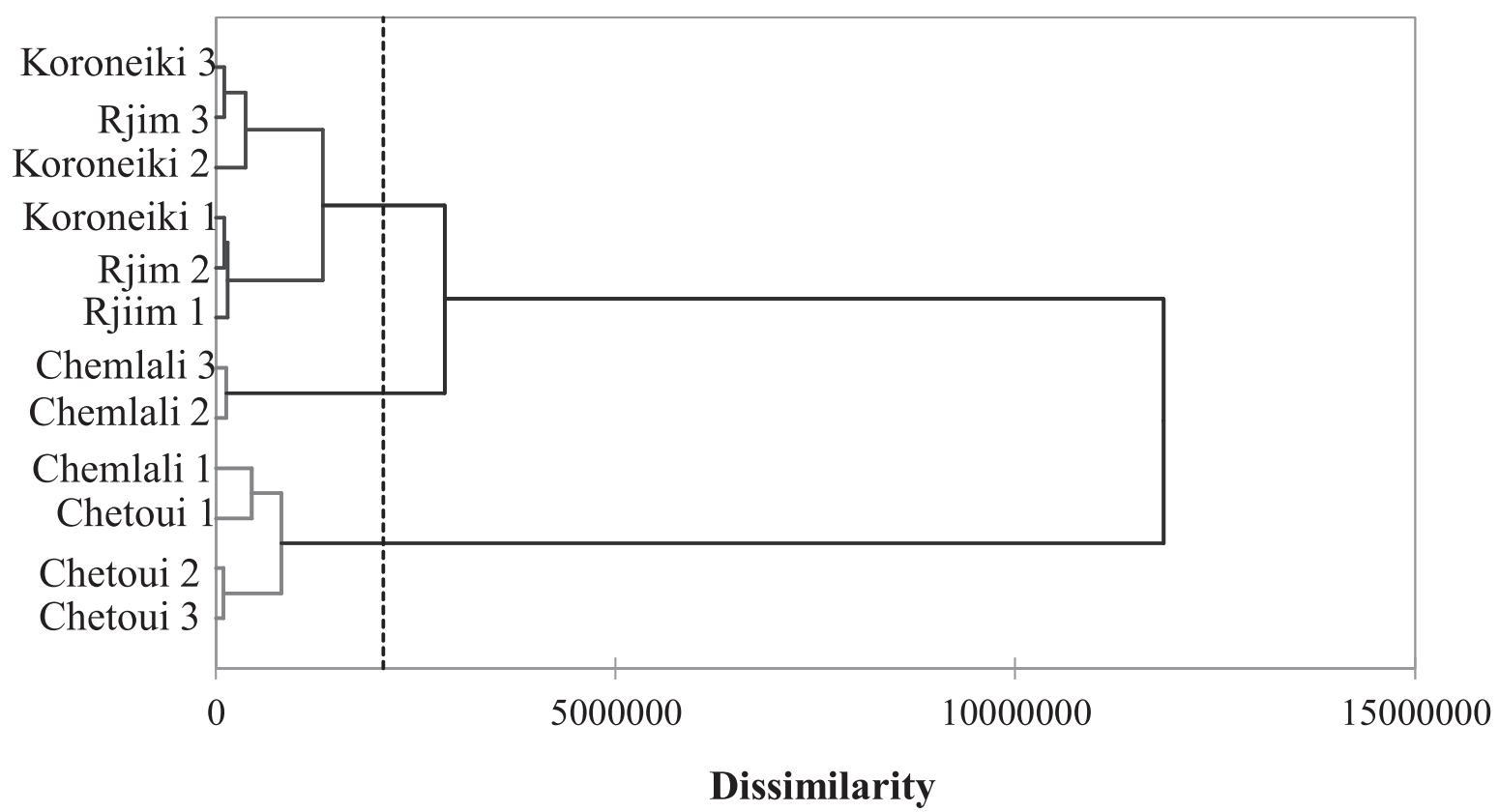

Fig. 3 Dendrogram of the Hierarchical Cluster Analysis (HCA) using all obtained data.

formation of clusters and its linkage could be compared and related to the groups formed in PCA (Fig. 3).

\section{Conclusion}

This work is the first evaluation of the potential of the main olive varieties (Chemlali, Chetoui, Koroneiki and Rjim)from Rjim Maatoug saharian oasis in southern Tunisia. The examined oils showed that oil quality degradation was mainly related to the great drought of climate in this desert region.

The application of SPME to the analysis of virgin olive oil headspace allowed the detection of significant differences in the proportions of volatile compounds from virgin olive oils tested in relation to olive ripening stages and severe climatic conditions. In all samples studied, the C6 aldehydes content which confers apple and green fruity attributes were very lower. These findings should not encourage the local people who are responsible for the sector to plant more olive trees without applying a solution to reduce high temperature effect during the lipogenesis period in Rjim Maatoug region.

Acknowledgements

The authors would like to thank the Ministry of Higher Education and Scientific Research of Tunisia(Contract programme LR14ES08), for their support of this research work. They also wish to extend their thanks to Mrs. Olfa FAKHFEKH, an English teacher, for having proofread this paper.

\section{References}

1) Gargouri, B.; Ammar, S.; Zribi A.; Ben Mansour, A.; Bouaziz, M. Effect of growing region on quality characteristics and phenolic compounds of Chemlali extravirgin olive oils. Acta Physiol. Plant. 35, 2801-2812 (2013).

2) Bouaziz, M.; Feki, I.; Ayadi, M.; Jemai, H.; Sayadi, S. Stability of refined olive oil and olive pomace oil added by phenolic compounds from olive leaves. Eur. J. Lipid Sci. Technol. 112, 21-24(2010).

3) Baccouri, O.; Guerfel, M.; Baccouri, B.; Cerretani, L.; Bendini, A.; Lercker, G. Chemical composition and oxidative stability of Tunisian monovarietal virgin olive oils with regard to fruit ripening. Food Chem. 19, 743754 (2008).

4) Kandylis, P.; Vekiari, A.S.; Kanellaki, M.; Grati Kamoun, N.; Msallem, M.; Kourkoutas, Y. Comparative study of extra virgin olive oil flavor profile of Koroneiki variety (Olea europaea var. Microcarpa alba) cultivated in Greece and Tunisia during one period of harvesting. LWT-Food. Sci. Technol. 44, 1333-1341(2011).

5) Dabbou, S.; Rjiba, I.; Nakbi, A.; Gazzah, N.; Issaoui, M.; Hammami, M. Compositional quality of virgin olive oils from cultivars introduced in Tunisian arid zones in comparison to Chemlali cultivars. Sci. Horticult. 124, 122-127 (2010).

6) Covas, M.I.; Ruiz-Gutiérrez, V.; De la Torre, R.; Kafatos, A.; Lamuela-Raventós, R.M.; Osada, J.; Owen, R.W.; Visioli, F. Minor components of olive oil: evidence to date of health benefits in humans. Nutr. Rev. 64, 20-30 (2006).

7) Bendini, A.; Cerretani, L.; Carrasco-Pancorbo, A.; Go- 
mez-Caravaca, A.M.; Segura-Carretero, A.; Fernandez Gutierrez, A. Phenolic molecules in virgin olive oils: a survey of their sensory properties, health effects, antioxidant activity and analytical methods. Molecules 12, 1679-1719(2007).

8) Morello, J.R.; Romero, M.P.; Motilva, M.J. Effect of the maturation process of the olive fruit on the phenolic fraction of drupes and oils from Arbequina, Farga and Morrut cultivars. J. Agric. Food Chem. 52, 6002-6009 (2004).

9) Beltran, G.; Aguilera, M.P.; Del Rio, C.; Sanchez, S.; Martinez, L. Influence of fruit ripening process on the natural antioxidant content of Hojiblanca virgin olive oils. Food Chem. 89, 207-215 (2005).

10) Lazzez, A.; Perri, E.; Caravita, M.A.; Khlif, M.; Cossentini, M. Influence of olive maturity stage and geographical origin on some minor components in virgin olive oil of the Chemlali variety. J. Agric. Food Chem. 56, 982-988 (2008).

11) Kalua, C.M.; Allen, M.S.; Bedgood, D.R.; Bishop, A.G.; Prenzler, P.D.; Robards, K. Olive oil volatile compounds, flavour development and quality: a critical review. Food Chem. 100, 273-286 (2007).

12) Vichi, S.; Castellote, A.I.; Pizzale, L.; Conte, L.S.; Buxaderas, S.; Lopez-Tamames, E.; Analysis of virgin olive oil volatile compounds by headspace solid-phase microextraction coupled to gas chromatography with mass spectrometric and flame ionization detection. $J$. Chromatogr: 983, 19-33 (2003).

13) Angerosa, F.; Influence of volatile compounds on virgin olive oil quality evaluated by analytical approaches and sensor panels. Eur. J. Lipid Sci. Technol. 104, 639-660 (2002).

14) Campeol, E.; Flamini, G.; Chericoni, S.; Catalano, S.; Cremonini, R. Volatile compounds from three cultivars of Oleaeuropea from Italy. J. Agric. Food Chem. 49, 5409-5411 (2001).

15) Ranalli, A.; De Mattia, G.; Patumi, M.; Proietti, P. Quality of virgin olive oil as influenced by origin area. Grasas Aceites 50, 249-259 (1999).

16) Ammar, S.; Zribi A.; Ben Mansour, A.; Ayadi, M.; Abdelhedi, R.; Bouaziz, M. Effect of Processing Systems on the Quality and Stability of Chemlali Olive Oils. $J$. Oleo Sci. 63, 311-323 (2014).

17) Vekiari, S.A.; Papadopoulou, P.; Kiritsakis, A. Effects of processing methods and commercial storage conditions on the extra virgin olive oil quality indexes. Grasas Aceites 58, 237-242 (2007).

18) Boskou, D. in Olive oil Chemistry and technology (Boskou, D. ed.) Champaign, IL: AOCS Press, pp. 53-83 (1996).

19) International Olive Council(IOOC). Trade standard applying to olive oils and olive pomace oils. COI/T, 15/ NC n’ 3 Rev 7 (2013). Principe de Vergara, 154, 28002,
Madrid, Spain.

20） Minguez-Mosquera, M.I.; Rojas, B.G.; Fernandez, J. G.; Guerro, L.G.J. Pigments present in virgin olive oil. $J$. Am. Oil Chem. Soc. 67, 192-196(1990).

21) Chtourou, M.; Gargouri, B.; Jaber, H.; Bouaziz, M. Comparative Study of Olive Oil Quality from Chemlali Sfax Arbequina cultivated in Tunisia. Eur. J. Lipid Sci. Technol. 115, 631-640 (2013).

22) Dridi Gargouri, O.; Gargouri, B.; Kallel Trabelsi, S.; Bouaziz, M.; Abdelhèdi. R. Synthesis of 3-O-methylgallic acid a powerful antioxidant by electrochemical conversion of syringic acid. Biochim. Biophys. Acta 1830, 3643-3649 (2013).

23) Adams, R.P. Identification of Essential Oil Components by Gas Chromatography/Mass Spectroscopy. 4th ed. Allured Publishing Corporation, Carol Stream, IL, USA (2007).

24) Flamini, G.; Cioni, P.L.; Morelli, I. Volatiles from leaves, fruits, and virgin oil from Olea europaea Cv. Olivastra Seggianese from Italy. J. Agric. Food Chem. 51, 13821386 (2003).

25) Gutiérrez, F.; Jimenez, B.; Ruiz, A.; Albi, M.A. Effect of olive ripeness on the oxidative stability of virgin olive oil extracted from the varieties Picual and Hojiblanca and on the different components involved. J. Agric. Food Chem. 47, 121-127(1999).

26) Rondanini, D.P.; Castro, D.N.; Searles, P.S.; Rousseaux, M.C.; Fatty acid pro- files of varietal virgin olive oils (Olea europaea L.) from mature orchards in warm arid valleys of Northwestern Argentina (La Rioja). Grasas Aceites 62, 399-409 (2011).

27) Saour, G.; Makee, H. Effects of kaolin particle film on olive fruit yield, oil content and quality. Adv. Hortic. Sci. 17, 204-206 (2003).

28) Ben Mansour, A.; Gargouri, B.; Flamini, G.; Bouaziz, M. Effect of agricultural sites on differentiation between Chemlali and Neb Jmel olive oils. J. Oleo. Sci. 64, 381$392(2015)$.

29) Skevin, D.; Rade, D.; Strucelj, D.; Mokrovcak, Z.; Nederal, S.; Benãiç, D. The influence of variety and harvest time on the bitterness and phenolic compounds of olive oil. Eur. J. Lipid Sci. Technol. 105, 536-541 (2003).

30) Laroussi-Mezghani, S.; Vanloot, P.; Molinet, J.; Dupuy, N.; Hammamib, M.; Grati-Kamoun, N.; Artaud, J. Authentication of Tunisian virgin olive oils by chemometric analysis of fatty acid compositions and NIR spectra. Comparison with Maghrebian and French virgin olive oils. Food Chem. 173, 122-132 (2015).

31) Ammar, S.; Zribi A.; Gargouri, B.; Flamini, G.; Bouaziz, M. Effect of Addition of Olive Leaves before Fruits Extraction Process to Some Monovarietal Tunisian ExtraVirgin Olive Oils Using Chemometric Analysis. J. Agric. Food Chem. 62, 251-263(2014). 
32) Bouaziz, M.; Chamkha, M.; Sayadi, S. Comparative study on phenolic content and antioxidant activity during maturation of the olive cultivar Chemlali from Tunisia. J. Agric. Food. Chem. 52, 5476-5481 (2004).

33) Ben Youssef, N.; Zarrouk, W.; Carrasco-Pancorbo, A.; Ouni, Y.; Segura-Carretero, A.; Fernandez-Gutierrez, A.; Daouda, D.; Zarrouka, M. Effect of olive ripeness on chemical properties and phenolic composition of chétoui virgin olive oil. J. Sci. Food Agric. 90, 199$204(2010)$.

34) Caponio, F.; Gomes, T.; Pasqualone, A. Phenolic compounds in virgin olive oils: Influence of the degree of olive ripeness on organoleptic characteristics and shelf-life. Eur. Food. Res. Technol. 212, 329-333 (2001).

35) Salvador, M.D.; Aranda, F.; Fregapane, G. Influence of fruit ripening on Cornicabra virgin olive oil quality: a study of four crop seasons. Food Chem. 73, 45-53 (2001).

36) Morello, J.R.; Romero, M.P.; Ramo, T.; Motilva, M.J. Evaluation of L-phenyllanine ammonia-lyase activity and phenolic profile in olive drupe from fruit setting period to harvesting time. Plant Sci. 168, 65-72 (2005).

37) Bakhouche, A.; Lozano-Sánchez, J.; Bengana, M.; Fernández-Gutiérrez, A.; Segura-Carretero, A. Time course of Algerian Azeradj extra-virgin olive oil quality during olive ripening. Eur. J. Lipid Sci. Technol. 117,
389-397 (2015).

38) Angerosa, F.; Basti, C. Olive oil volatile compounds from the lipoxygenase pathway in relation to fruit ripeness. Ital. J. Food Sci. 13, 421-428(2001).

39) Baccouri, O.; Bendini, A.; Cerretani, L.; Guerfel, M.; Baccouri, B.; Lercker, G.; Zarrouk, M.; Daoud Ben Miled, D. Comparative study on volatile compounds from Tunisian and Sicilian monovarietal virgin olive oils. Food Chem. 111, 322-328(2008).

40) Aparicio, R.; Morales, M.T. Characterization of olive ripeness by green aroma compounds of virgin olive oil. J. Agric. Food Chem. 46, 1116-1122 (1998).

41) Angerosa, F.; D’Alessandro, N.; Basti, C.; Vito, R. Biogeneration of volatile compounds in virgin olive oil: Their evolution in relation to malaxation time. $J$. Agric. Food Chem. 46, 2940-2944(1998).

42) Ben Temime, S.; Campeol, E.; Cioni, P. L.; Daoud, D.; Zarrouk, M. Volatile compounds from Chétoui olive oil and variations induced by growing area. Food Chem. 99, 315-325 (2006).

43) Luna, G.; Morales, M.T.; Apaaricio, R. Characterization of 39 varietal virgin olive oils by their volatile compositions. Food Chem. 98, 243-252 (2006).

44) Oueslati, I.; Anniva, C.; Daoud, D.; Tsimidou, M.Z.; Zarrouk. M. Virgin olive oil (VOO) production in Tunisia: The commercial potential of the major olive varieties from the arid Tataouine zone. Food Chem. 112, 733741 (2009). 